\title{
Distance Learning Experience During Covid-19 Period in Higher Education for Space Application
}

\author{
Poonam S. Tiwari ${ }^{1} \cdot$ Harish Karnatak ${ }^{1} \cdot$ Shefali Agarwal $^{1} \cdot$ Kamal Pandey $^{1} \cdot$ Janardan Vishwakarma $^{1} \cdot$ \\ Ashok Ghildiyal ${ }^{1} \cdot$ Prakash Chauhan ${ }^{1}$
}

Received: 27 November 2020 / Accepted: 4 July 2021 / Published online: 17 July 2021

(C) Indian Society of Remote Sensing 2021

\begin{abstract}
Distance learning is the process of creating an educational experience of equal qualitative value for the learner to best suit their needs outside the classroom. Distance Learning Program (DLP) offered by Indian Institute of Remote Sensing (IIRS), Indian Space Research Organisation (ISRO), has witnessed steady growth in the last thirteen years benefitted more than 2.65 lakh participants from 2650 network institutes distributed across the country. Under this program, IIRS has successfully established a network of academic and professional Institutions in the country. The Covid-19 pandemic has affected higher education severely. India was under complete lockdown during April and May 2020. In this scenario, to ensure uninterrupted and safe access to learning, IIRS has responded to the crisis by tapping into its existing DLP. During the lockdown and post-lockdown period, IIRS conducted 11 Live and Interactive course/workshop/webinars focusing on Basics and Advanced topics related to Geospatial technology. During this period, IIRS DLP witnessed an exponential growth in terms of number of participation, number of participating institutes and also the percentage of working professionals. IIRS DLP witnessed a fivefold growth in participation benefitting around 57,000 participants from across the country. The number of network institutes also grew by 50\% during April-June 2020. Statistics indicate that during January-June IIRS outreach program witnessed 22-fold growth in number of professionals joining the courses. Also, the overall feedback of the course by participants was very encouraging. Even though there are times when nothing can replace the personal attention of a teacher, in the current situation the focus is on utilizing technology effectively for uninterrupted learning.
\end{abstract}

Keywords Distance learning · Virtual class · Geospatial technology · Covid-19

Poonam S. Tiwari

poonam@iirs.gov.in

Harish Karnatak

harish@iirs.gov.in

Shefali Agarwal

shefali_a@iirs.gov.in

Kamal Pandey

kamal@iirs.gov.in

Janardan Vishwakarma

janardan@iirs.gov.in

Ashok Ghildiyal

ashok@irs.gov.in

Prakash Chauhan

prakashchauhan@iirs.gov.in

1 Indian Institute of Remote Sensing, Indian Space Research Organisation, 4 Kalidas Road, Dehradun, India

\section{Introduction}

The contemporary world is witnessing a revolution in every field including education aided by advancements in Information and communication technology (Delgado et al., 2010). This has led to various convenient means to help increase the knowledge, education and literacy status of people through the E-learning platforms which provide easy and accessible means for upgrading skills (Dutton et al., 2005; Englund et al., 2017). Digital learning enables the individual to acquire competencies in relevant areas through a self-paced method (Hanewald et al., 2011; Hiltz et al., 2005; Parker et al., 2011). Though digital learning arrived a bit late in India, it is being embraced enthusiastically and is coming up in a big way. Over the past few years, the government of India through its policy of Digital 
India has been promoting such endeavors to popularize digital leaning environment.

The advent of the second decade of the century has witnessed a worldwide phenomenon which has had far reaching affects globally. The Covid-19 pandemic is a global phenomenon and has affected all sectors throughout the world, including higher education (Alawamleh, 2020). India has been also severely affected by this pandemic (Crawford et al., 2020). Institutes of higher education like Universities and colleges were abruptly closed resulting in abandonment of teaching of ongoing courses (Bao, 2020; Chick et al., 2020). According to UNESCO, on April 1, 2020, schools and higher education institutions (HEIs) were closed in 185 countries, affecting 1.5 billion learners, which constitute $89.4 \%$ of total enrolled learners (Daniel, 2020; Ferdig et al., 2020; Murphy, 2020). By now, some countries, experiencing decreasing numbers of cases and deaths, have started lifting confinement measures. However, as of July 2020, schools and higher education institutions (HEIs) were still closed in 177 countries, affecting 1.2 billion learners, which constitute $72.4 \%$ of total enrolled learners (https://www.iau-aiu.net/IMG/pdf/iau_ covid19_and_he_survey_report_final_2020.pdf). Government of India imposed a nationwide lockdown on March 25, 2020, to deal with the pandemic. Even before the lockdown, colleges were shut down. Since March 25th, India was in state of complete/partial lockdown till June 1, 2020, and even after the unlock procedure, the regular classes have not resumed in the colleges (Manthalkar \& Joshi, 2020). The uncertainty towards the resumption of regular academic activity and prolonged disturbance in the academic calendar has led to re-invention of teaching learning strategy. The National Council of Applied Economic Research (NCAER) deliberated over the prospective of utilizing online learning for complementing the traditional teaching methods. However, in the current situation, online education is turning out to be a substitute to traditional modes.

\section{IIRS Outreach Program}

Learning being the acquisition of knowledge, is not dependent on the method of teaching (Collins \& Halverson, 2018; Moore et al., 2011). The focus is on creating environment and providing students an experience which aids their learning by imparting knowledge and developing skills (Weller \& Anderson, 2013). IIRS outreach program is an innovative distance learning initiative for training professionals from academia and user departments in the field of geospatial technology \& Earth Observation by utilizing state-of-the-art Information and communication technology (Krishna Murthy et al., 2014, Karnatak et al.,
2017). Since its inception in 2007, IIRS outreach program has grown significantly and till December 2020, IIRS has successfully conducted $\mathbf{7 2}$ outreach programs through live and interactive classrooms (also known as EDUSAT program) benefitted more than $\mathbf{2 . 6 5}$ lakh participants from 2650 network institutes distributed across the country. During last thirteen years, IIRS has successfully established a network of academic and professional Institutions in the country under this program.

The present distance learning program of IIRS is being conducted through following two major modes, namely Live and Interactive classroom sessions and E-learningbased online courses. IIRS Live and Interactive program is most popular among the student community (Karnatak et al., 2017). These courses are conducted through indigenous learning management system "E-CLASS." IIRS live and interactive program endorses blended learning which combines classroom and online learning. The interaction between IIRS and course participant is facilitated by a nodal coordinator. The mode of conduction of live and interactive courses is explained in Fig. 1

The major objective of this program is strengthening academia and user segment in space technology \& its applications using online learning platforms. To achieve this objective, IIRS has developed a strong country wide academia interface under its outreach program. A network of academic and professional Institutions in India where each network Institute is known as "IIRS Nodal Centre (INC)" has been setup. Currently, 2669 nodal centers are networked with IIRS. The country wide spatial distribution of these networked Institutions is shown in Figs. 2, 3, and participation from different types of Institutions is shown in Fig. 2

The content of IIRS Distance Learning Program focuses on teaching basic concepts along with technological advancement in the field of RS, GIS, GNSS and its applications. The sessions are interactive and majority of such sessions/lectures in DLP courses are delivered by subject experts from IIRS and guest faculty from other ISRO centers. IIRS has also developed its own indigenous active learning platform, i.e. Electronic Collaborative Learning And Knowledge Sharing System (E-CLASS). E-CLASS provides various online learning tools and services for coordinators of networked institutions and online learners. All the courses are made available through E-CLASS which enables the participants to attend live sessions, post queries, download study material, attend offline sessions, appear for online exam and download certificate. Figure 4 illustrates the home page, offline sessions, discussion forum and online quiz available through E-CLASS. The entire course management is fully automated with innovating learning tools such as registration, student approval, daily attendance marking and 


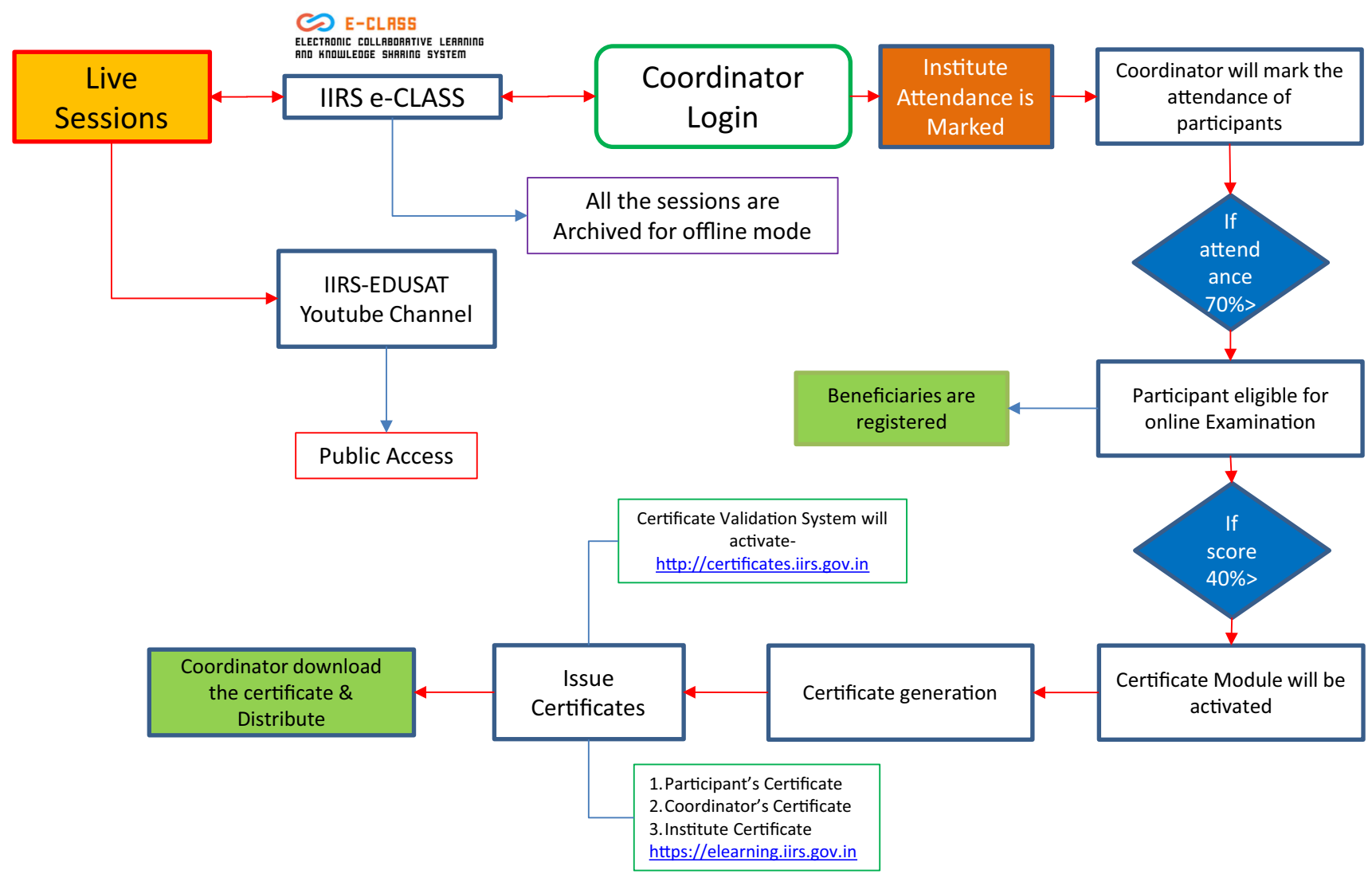

Fig. 1 IIRS Live and Interactive Program: Mode of conduction

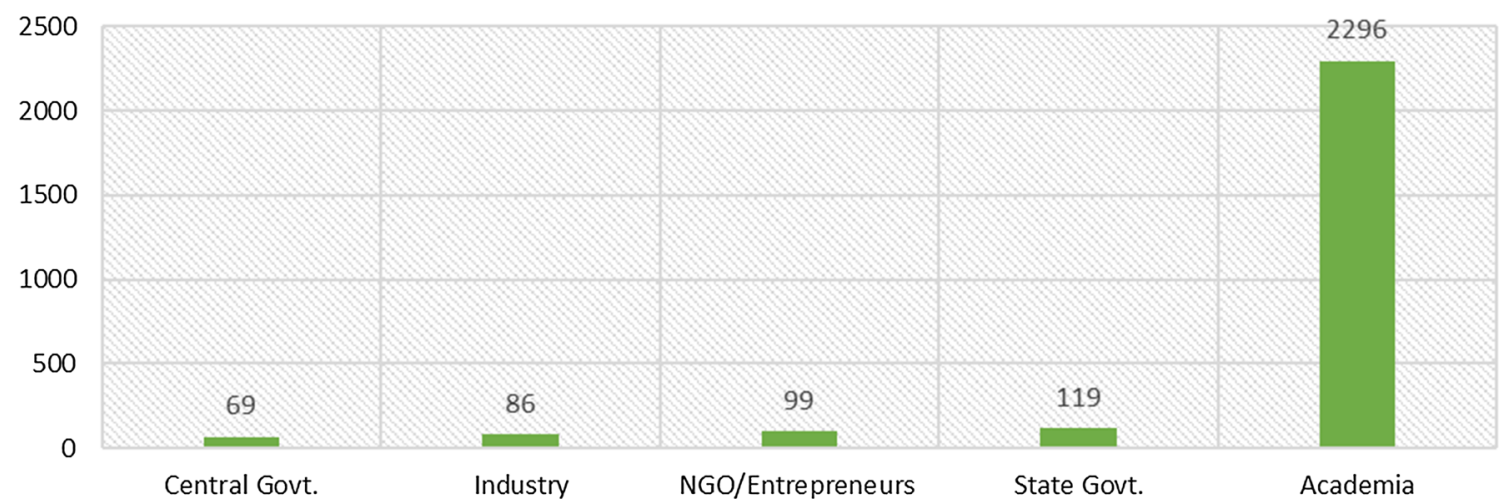

Fig. 2 Categorization of Institutions networked with IIRS outreach program

monitoring, live lecture and interaction, chat room, audio/ video interactions and online quiz as class activity for attention grabbing of the learners. E-CLASS has been developed by using open source software technology and open system architecture. The open source platform such as Angular, NodeJs, MySQ1, MongoDB, Nginx web server are used as software development environment.

As per the defined Standard Operating Protocol (SOP) of IIRS, one senior faculty or officer is identified as INC coordinator who is responsible for coordination of different online courses conducted by IIRS. In pre-lockdown scenario, the identified coordinator used to conduct the live classes at his/her Institute and invites interested participants to join the online course in a group. The coordinator acts as a moderator for respective center and is also responsible for submitting daily attendance of the participants through IIRS E-CLASS portal. The participants who satisfy minimum attendance criteria are eligible for online examination. During the live session, the participants could put up their doubts and queries to the expert ask their doubts to the expert panel and faculty. The coordinator of IIRS nodal center conducts online examination under their 


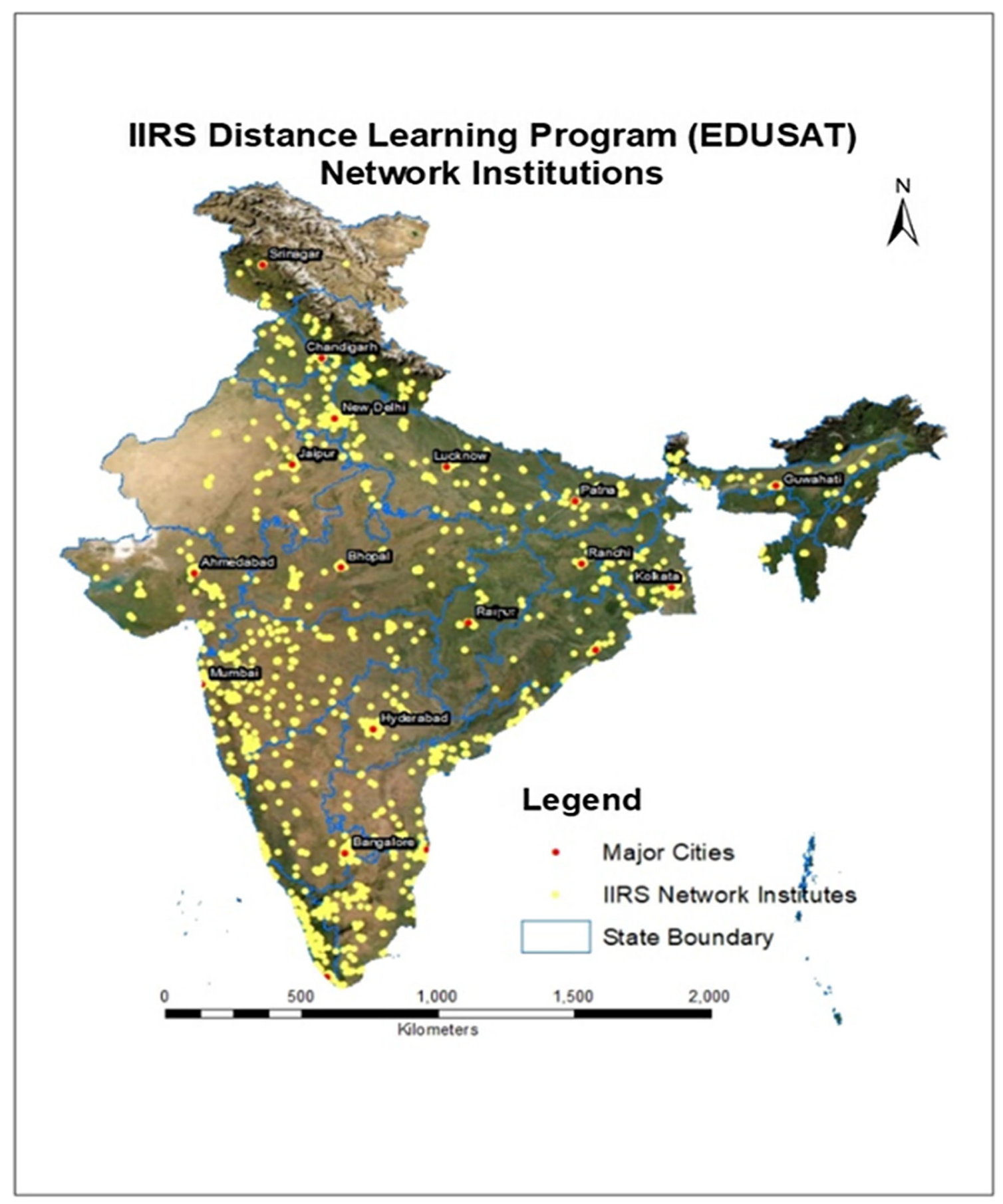

Fig. 3 Spatial distribution of Network Institutions in India under IIRS DLP

supervision. The participants scoring minimum passing grades are eligible for course completion certificate.

IIRS team has worked towards efficient and effective management of the virtual sessions by adopting best practice measures. Pre-session briefing and reminder messages are sent to participants to ensure smooth conduction and participation. During sessions, an effort is made to bridge the physical gap between learner and instructor. For this various measures such as attendance monitoring, engaging the participants in class activity through online quiz, providing chat forum for technical discussion, live interaction at end of each session and panel discussion at the end of course are adopted. The concepts are explained through live lectures including suitable illustrations and animations. Theory sessions are complemented with practical demonstrations and hands on exercises. Flexibility of 

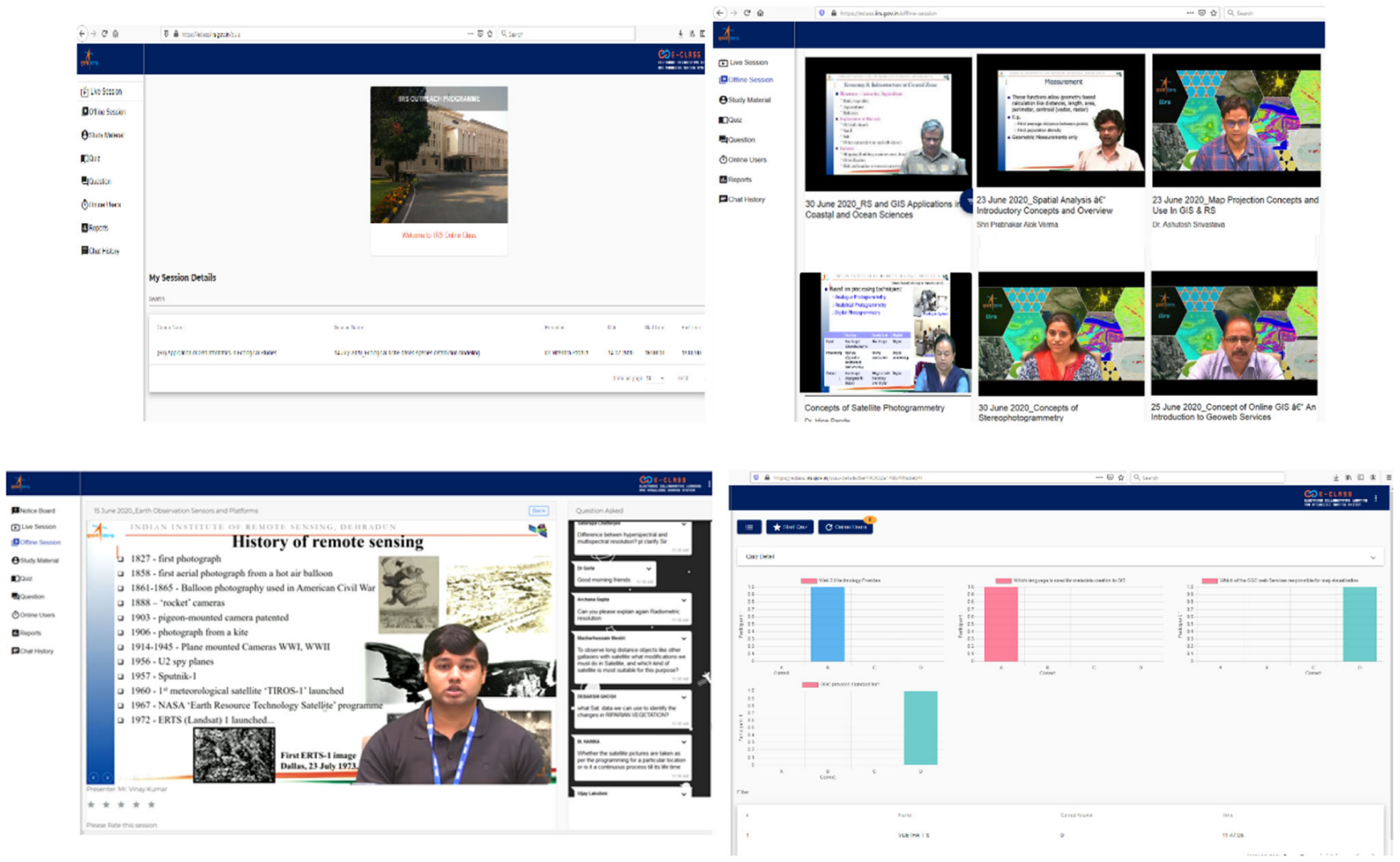

Fig. 4 E-CLASS: Home Page, Offline Session, Discussion Forum and Online Quiz

attending sessions in offline mode is provided keeping in mind technical constraints at learner end. To ensure proper assimilation of concepts, at the end of the course, an online examination is conducted.

During last thirteen years, IIRS distance learning program has recorded significant growth in terms of number of participants and number of participating Institutions in the online courses. At the same time, the number courses offered by IIRS has also increased to meet the large user requirements. The number of participants registered each year is shown in Fig. 5. The figure clearly depicts the increase in participation in IIRS online courses highlighting popularity of these programs among the learners.

\section{IIRS Initiatives and Outcome During Covid- Induced Lockdown}

While the entire world imposed complete or partial lockdown because of the Covid-19 pandemic, businesses have adapted to work-from-home (WFH) policies with varying degree of success. Education sector has also forcibly undergone a dramatic change, with the distinctive rise of e-learning, whereby teaching is undertaken remotely and on digital platforms. In the current scenario, IIRS has responded to the present crisis by tapping into its existing
Distance Learning Program (DLP) with following modifications in the procedure:

\section{Individual Logins and Student Monitoring Approach}

In the pre-lockdown scenario, the sessions were organized by coordinators at their respective centers where number of students participated in the class activity through a single classroom login. However, during the lockdown as colleges and institute are closed indefinitely, each participant through registered through a network institute has been provided with individual login to access the live sessions. This has created immense pressure on the existing hardware and network infrastructure available at IIRS. IIRS team has redesigned the software system architecture of E-CLASS platform to accommodate large number of simultaneous logins during the live sessions. The clusterbased system architecture was adopted to enhance the performance of the system.

The monitoring of student progress during online courses is another important task which was addressed by developing new methods of attendance recording. The student attendance is monitored online based on the onscreen time. Considering the problems in internet connectivity for participants, the participants were allowed to 


\section{Year wise number of Participants}

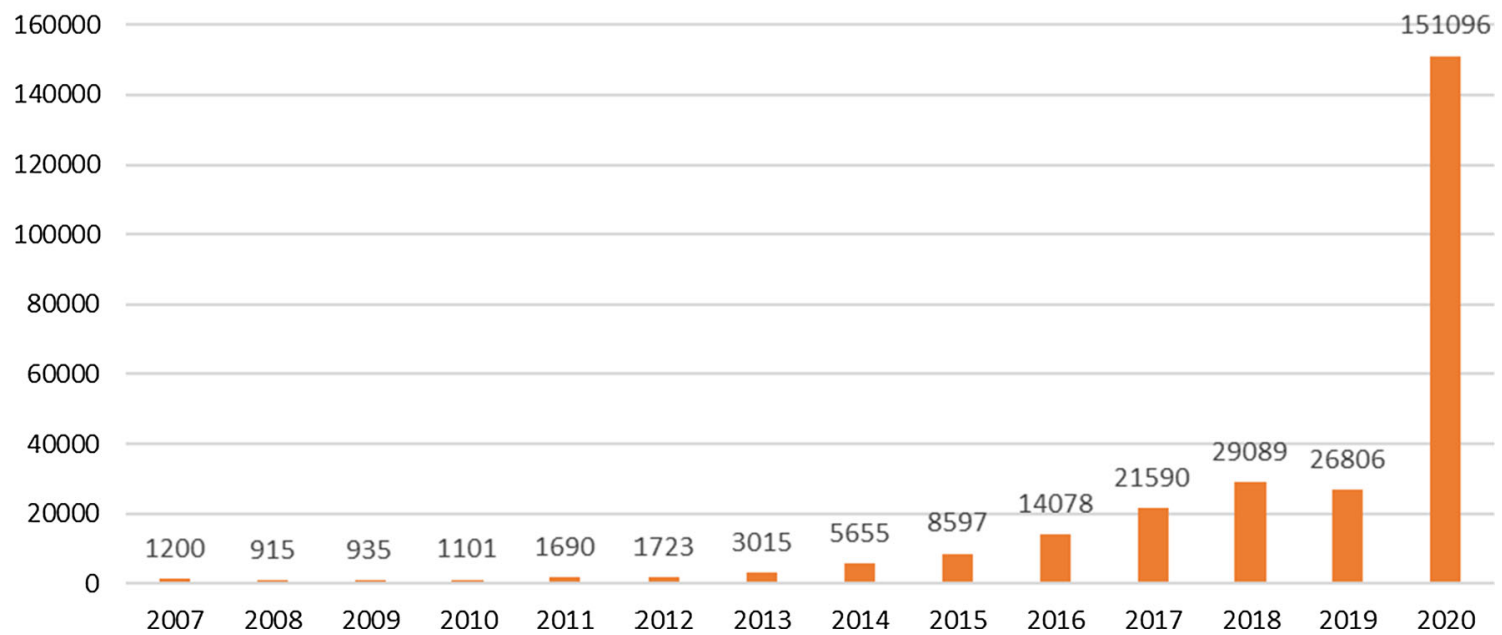

Fig. 5 Year wise growth of the participants in IIRS online courses. * Course for 2020 are in progress

watch $40 \%$ sessions in offline mode. The video archive of all the live sessions with question module of live session was developed and updated on daily basis. Flexibility of attending sessions in offline mode is provided keeping in mind technical constraints at learner end.

\section{Change in Examination Policy}

To ensure proper assimilation of concepts, at the end of the course, an online examination is conducted after each course. Before the colleges were shut down due to Covid19-induced lockdown the examinations were conducted by coordinators at their respective centers. The quiz password was provided to the coordinators and they were responsible for invigilation during the examination. However, due to prevailing pandemic situation in the country students are attending the course from their respective residences. Hence invigilation during the examination is not possible. IIRS management has decided to suspend examination for IIRS DLP courses till further notice. The participants are receiving a Certificate of participation based on their attendance in the course. However, the online examinations were available as self-assessment system and learners were encouraged to participate in the examination.

\section{Conduction of Live Quiz as Class Activity}

To make the learners active during live sessions, IIRS has developed class activity module in E-CLASS platform. The random quiz was conducted after 20-25 min of live sessions. The participant's activity and response is recorded in the server for further evaluation purposes.

The innovative specialized courses announced by IIRS during Covid-19 lockdown has grab the attention of online learners and also print and electronic media. This resulted in an exponential growth in terms of number of participation in IIRS Distance learning courses.

To get a clear understanding of effect of Covid-induced lockdown on IIRS outreach programs, data for January to June period of the years 2017 to 2020 were analyzed.

During January to June 2020, IIRS conducted 11 Live and Interactive course/workshop/webinars benefitting around 57,000 participants from all corners of the country. This amounts to a fivefold growth from previous year's participation. During pre-lockdown period (January-March 2020), three courses were offered through DLP, whereas during the lockdown (April to June 2020) IIRS offered eight courses on variety of technical and application areas related to Geospatial technology. Figure 6 depicts the growth of DLP participation during January-June for the years $2017-2020$.

One of the most popular programs among the student community, Basic Principles in RS and GIS, was offered as a two week capsule course during the lockdown period (April 13-25, 2020). The target participants were students of undergraduate and postgraduate courses, professionals of Central/State Government Ministries/Departments and faculty/researchers at university/Institutions. The course focused on use of Remote Sensing, Geographical Information System, Global Navigation Satellite System and associated geospatial technologies. The program was attended by more than 7500 participants and was well received. More than $90 \%$ of the participants appreciated the structure, syllabus and mode of conduction of the course.

Based on the large number of participation and on positive feedback and request by the participants, several more such programs were initiated. During May and June 
Fig. 6 a Year-wise courses and b) participation in IIRS distance learning program during January-June, (2017-2020)
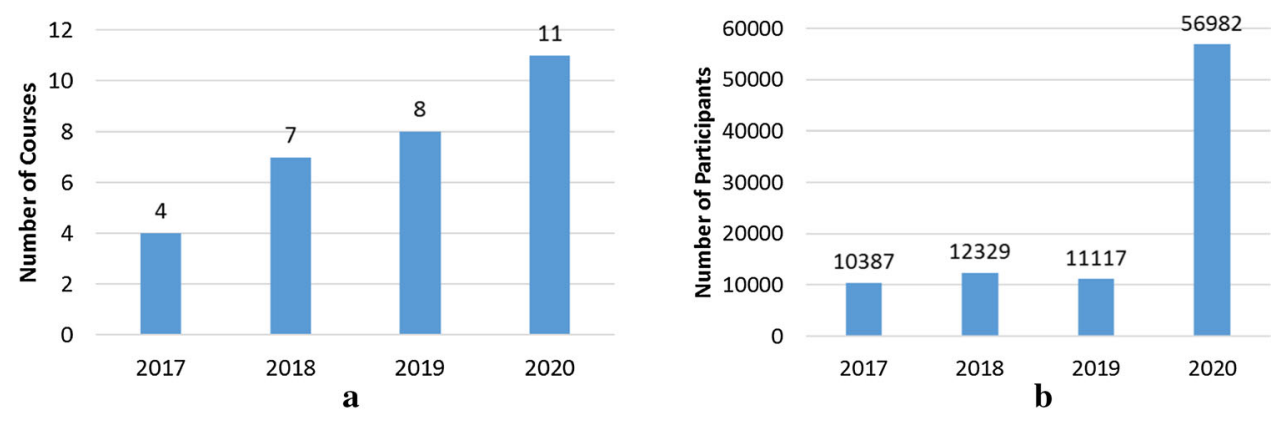

* Course for 2020 are in progress
2020, IIRS conducted additional programs on various themes, viz. Basics of SAR Remote Sensing, Remote Sensing in Crop Monitoring (International Webinar), Machine Learning (workshop), Remote Sensing \& GIS Technology and Applications (University Teachers \& Government Officials), Overview of Planetary Geoscience with special emphasis to Moon and Mars, Health GIS and Satellite Photogrammetry and its Applications. IIRS also conducted special courses designed for specific user organization. The officials of the organizations were able to learn the technological concepts in an e-learning mode without travelling to IIRS and being away from their work place. Since the participants registered for regular courses of IIRS were sent back home, their classes were also conducted using this mode. One of the on-campus courses for university teachers was offered as a capsule program and was well received with a huge participation of nearly 4500 university faculty. The courses offered by IIRS DLP witnessed an exponential increase in participation with more than 9500 participants joined various courses during May and around 36,500 during June 2020. Summary of courses and participation during January-June 2020 is shown in Fig. 7.

During the period of study, IIRS witnessed a surge in number of networked institutes joining the DLP network. In previous years (2017-2019), an average of 80 new institutes had joined IIRS network during January-June; however, in the year 2020 this number has increased to 631of which majority (557) had joined in the month of June 2020 . The number of network institutes grew by $50 \%$ during April-June 2020. As of June 2020, around $1800+$ institutes were connected to IIRS distance learning network. A graphical representation is shown in Fig. 8.

Even though IIRS Distance Learning Program started with an objective of complementing Indian University education, over the years it has witnessed increased participation from professionals working in the area of RS and GIS. Statistics indicate 22-fold increase in the participation of professionals during January-June 2019 and 2020. In the year 2019, 597 professionals joined the courses during January to June, while around 13,500 professionals joined during the same duration in 2020. Even though the total participation of professionals has increased significantly, the participation from various government and nongovernment agencies was also analyzed. It was observed that the number of central government and state government officials has increased many folds; however, the percentage distribution is nearly same for central government institutes. Participation from state Government and Industry/Corporate/NGO has significantly increased, while the percentage participation from academic institutions has slightly declined. Figure 9 shows that the participation of professionals from academic institutions has declined marginally from $75.21 \%$ to 72.75 . This may be because of limited infrastructure at their homes as the educational institutes were closed. The central government participation has increased marginally from 8.04 to $9.92 \%$, whereas the participation from private industries increased considerably from 2.68 to $10.09 \%$. This increase could be attributed to work from home policy of various private
Fig. 7 ( a) Number of courses and (b) Participation in IIRS Distance Learning Program during January-June, 2020
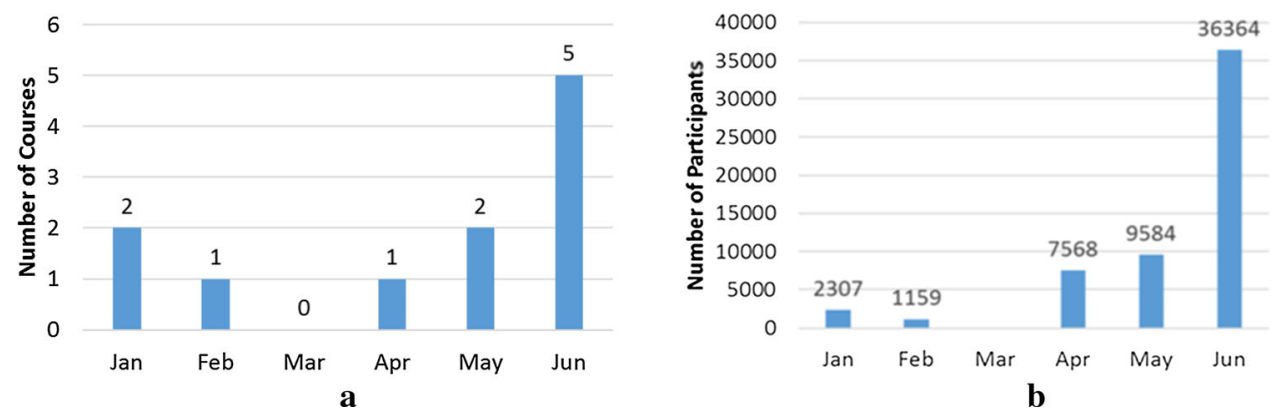
Fig. 8 ( a) Year-wise Comparative statistics of Additions in IIRS DLP Network Institutes (January to June)

(b) Increase in number of Institutions during January to June, 2020
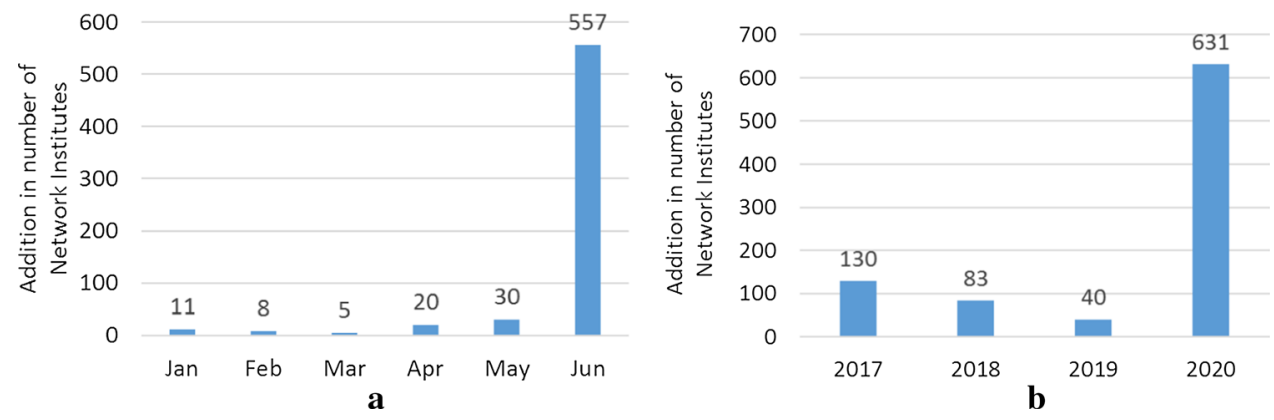

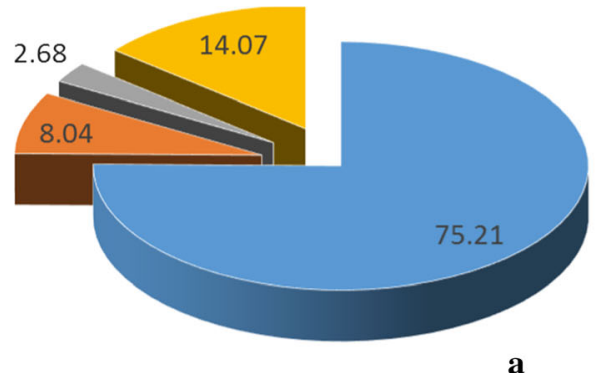

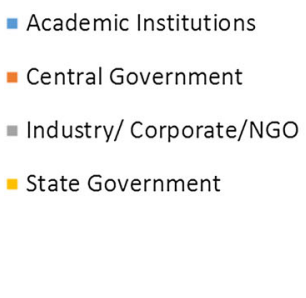

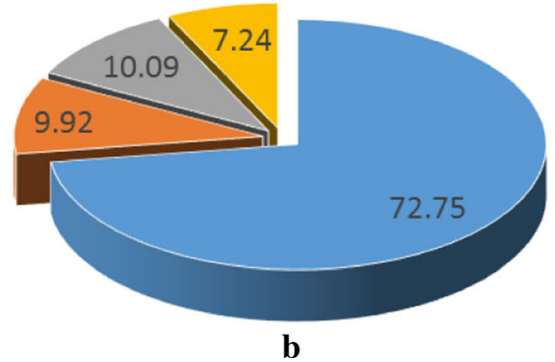

h

Fig. 9 Percentage Participation of Various Institutes during January-June (a) 2019; (b) 2020

industries during this period due to which the professionals could involve themselves for learning new technology and upgradation of skills. Figure 7 depicts participation of different institutes during January-June 2019 and 2020.

A few possibilities of sudden large number of increase in participation of in DLP during the period of study may be attributed to various reasons. A major reason could be due to closure of institute/colleges/offices and the individuals had time to learn new technology to gain awareness on the benefits and uses of geospatial technology. The programs offered through IIRS DLP were on topics related to latest technological advancements and thematic applications and highlighted the usefulness and applicability of the geospatial technology. This generated interest among working professionals and led them to enroll for IIRS programs.

At the end of each course, the participants provided their feedback regarding the course. Overall feedback of all courses under IIRS DLP was promising and encouraging. The participants found the sessions interesting and indicated that most of their doubts were answered by the faculty. The course content was appreciated by the participants for its depth and range. The session delivery by the experts which included theoretical concepts coupled with practical applications of the technology was highly appreciated. The participants have expressed their interest to participate in similar program for various thematic applications. IIRS initiatives of making learning available in the safety and comfort of their homes during lockdown period was well appreciated. Due to large number of participation, during the interactive session, the questions were moderated by subject expert. Some of the major difficulties raised by the participants are limited practical demonstrations and Internet connectivity issues at their end.

\section{Issues and Challenges}

With virtually every learner carrying a computer in their pocket in the form of a smartphone or tablet, digital or e-learning continues to be a key trend (Lai, 2011; Natriello, 2005). However, while technology is enabling the education, it can also be limiting factor, especially in India, where basic access to electricity and internet connectivity is a challenge. To overcome this shortcoming, IIRS distance learning programs are designed to be even accessible to participants through recorded material via IIRS learning portal "E-CLASS." With this approach, the objective has been to bring education opportunities to the learner's doorstep in the safety of their homes. In the pre-lockdown scenario, the sessions were organized by coordinators at their respective centers where number of students participated in the class activity through a single classroom login.

The IIRS online courses became very popular among the learners where large number of participants have participated in these courses. The online course of IIRS has attracted the all the sections of the society, and beneficiaries of these course vary from school students to senior citizens of the society. This year large number of working 
professional has also joined the online course of IIRS to enhance their technical skills to improve their work efficiency and career growth. The lockdown period was well utilized by many students and working professional by attending the live sessions and participating in discussions using innovating online learning tools. The different types of online courses/workshops/webinar series were conducted by IIRS by targeting different user groups in the society. The types and mode of online contents were continuously improved to maintain the interest of the learners. It was also observed that many participants are joining multiple courses offered by IIRS.

However, during the lockdown as colleges and institute are closed indefinitely, each registered participant is accessing live sessions individually using his/her login. This has created immense pressure on the existing hardware. Sometimes, the bandwidth limitations at the user-end also hinder smooth audio/video interaction. The E-CLASS platform of IIRS has emerged as an effective tools for teachers and online learners. The live sessions for large number of participants were successful conducted by using E-CLASS platform. IIRS has successfully scaled up the technology and IT infrastructure to meet the large user requirements. The cluster-based system architecture proved to be one of the best solutions for getting required performance of the system during live sessions.

Online classes tend to focus on theory rather than practical aspect. One of the critical gaps in conduction of online courses was limited practical experiments by the participants. Although sufficient number of demonstration was shown to participants during the courses, still it was reported as one of the limiting factors in the online course. The availability of virtual laboratory for the students may fill this gap. IIRS is putting effort to setup a virtual lab for online courses. To enhance the classroom experience for the participants, IIRS is working towards enabling audio interaction with the faculty. Since geospatial technology is a multidisciplinary subject relying heavily on using technology for solving real world problems and decision making, IIRS is working towards enhancing learning experience through practical demonstrations by developing theme specific case studies. In-depth assessment of candidates understanding of the subject is also challenging through online mode.

\section{Conclusions and Way Forward}

This unforeseen challenge has come with unknown dimensions in higher education, most particularly the technical infrastructure, the support tools to use for distance learning, assimilating online teaching pedagogies and finally how to organize and manage exams and student assessments from distance (Levy, 2003). Even though there are times when nothing can replace the personal attention of a teacher, in the current situation the focus is on utilizing technology for learning (Basilaia \& Kvavadze, 2020). In the future, approaches like integrated/blended learning and experiential learning, with greater implementation of technology, will empower the teaching community and shape the future of education in India. The fundamental purpose and intent is not the replacement of contact learning methods, rather to effectively complement and strengthen it by integrating the two methods carefully keeping the content and context in mind.

\section{References}

Alawamleh, M. (2020). COVID-19 and higher education economics. Journal of Economics and Economic Education Research, 21(2), $1-2$.

Bao, W. (2020). COVID-19 and online teaching in higher education: A case study of Peking University. Human Behavior and Emerging Technologies, 2(2), 113-115. https://doi.org/10.1002/ hbe 2.191

Basilaia, G., \& Kvavadze, D. (2020). Transition to online education in schools during a SARS-CoV-2 coronavirus (COVID-19) pandemic in Georgia. Pedagogical Research, 5(4), 1-9. https://doi. org/10.29333/pr/7937

Chick, R. C., Clifton, G. T., Peace, K. M., et al. (2020). Using technology to maintain the education of residents during the COVID-19 pandemic. Journal of Surgical Education. https://doi. org/10.1016/j.jsurg.2020.03.018

Collins, A., \& Halverson, R. (2009). Rethinking education in the age of technology: the digital revolution and the schools.

Crawford, J., Butler-Henderson, K., \& Rudolph, J. (2020). COVID19: 20 Countries' higher education intra-period digital pedagogy responses. Journal of Applied Teaching and Learning (JALT), 3(1), 1-20. https://doi.org/10.37074/jalt.2020.3.1.7.

Daniel, S. J. (2020). Education and the COVID-19 pandemic. Prospects. https://doi.org/10.1007/s11125-020-09464-3

Delgado-Almonte, M., Andreu, H. B., \& Pedraja-Rejas, L. (2010). Information technologies in higher education: Lessons learned in industrial engineering. Journal of Educational Technology \& Society, 13(4), 140-154.

Dutton, W.H., Loader, B. D. eds., (2005). Digital academe: New media in higher education and learning. Routledge.

Englund, C., Olofsson, A. D., \& Price, L. (2017). Teaching with technology in higher education: Understanding conceptual change and development in practice. Higher Education Research \& Development, 36(1), 73-87. https://doi.org/10.1080/ 07294360.2016.1171300

Ferdig, R.E., Baumgartner, E., Hartshorne, R., Kaplan-Rakowski, R. \& Mouza, C., (2020). Teaching, technology, and teacher education during the covid-19 pandemic: Stories from the field. Waynesville, NC, USA: Association for the Advancement of Computing in Education (AACE).

Hanewald, R., \& Ng, W. (2011). The digital revolution in education: Digital citizenship and multi-literacy of mobile technology. In Mobile technologies and handheld devices for ubiquitous learning: Research and pedagogy (pp. 1-14). IGI Global. https://doi.org/10.4018/978-1-61692-849-0.ch001 
Hiltz, S. R., \& Turoff, M. (2005). Education goes digital: The evolution of online learning and the revolution in higher education. Communications of the ACM, 48(10), 59-64.

https://www.iau-aiu.net/IMG/pdf/iau_covid19_and_he_survey_ report_final_2020.pdf Retrieved on July 2020.

Karnatak, H.C., Srivastav, S.K., Tiwari, P.S., Kumar, A.S., Vishwakarma, J., Kavitha N, Ghildiyal, A., Pandey, K. (2017).IIRS, ISRO. An innovative approach for mass level capacity building in Geospatial technology and its applications using online active learning platforms - ISPRS TC V/4 \& V/6: Online Platforms for Education \& Outreach, IIRS, ISRO, Special Session (SS-13: ISPRS TC V/4 \& V/6), ACRS-2017.

Krishna Murthy, Y. V. N., Raju, P. L. N., Srivastav, S. K., Karnatak, H., Kumar Gupta, P., Mahadevaswamy, M., \& Viswakarma, J. (2014). Reach the unreached -IIRS outreach program for enhanced learning to all, the international archives of the photogrammetry. Remote Sensing and Spatial Information Sciences, $X L-8,1243-1247$.

Lai, K.W. (2011) Digital technology and the culture of teaching and learning in higher education. Australasian Journal of Educational Technology. https://doi.org/10.14742/ajet.892

Levy, S., (2003). Factors to consider when planning online distance learning programs in higher education. In Online Journal of Distance Learning Administration, Spring.
Manthalkar, R., Gajre, S. \& Joshi, Y. (2020). Education after COVID19 Disruption (No. 3431). EasyChair.

Moore, J. L., Dickson-Deane, C., \& Galyen, K. (2011). e-Learning, online learning, and distance learning environments: Are they the same? The Internet and Higher Education, 14(2), 129-135. https://doi.org/10.1016/j.iheduc.2010.10.001

Murphy, M. P. (2020). COVID-19 and emergency eLearning: Consequences of the securitization of higher education for post-pandemic pedagogy. Contemporary Security Policy. https:// doi.org/10.1080/13523260.2020.1761749

Natriello, G. (2005). Modest changes, revolutionary possibilities: Distance learning and the future of education. Teachers College Record, 107(8), 1885.

Parker, K., Lenhart, A. \& Moore, K. (2011) The digital revolution and higher education: College presidents, public differ on value of online learning. Pew Internet \& American Life Project.

Weller, M., \& Anderson, T. (2013). Digital resilience in higher education. European Journal of Open, Distance and E-Learning, 16(1), 53.

Publisher's Note Springer Nature remains neutral with regard to jurisdictional claims in published maps and institutional affiliations. 